\title{
Influence of direct electric field on PMCG-alginate-based microcapsule
}

\author{
Peter Kasak $^{1}$ (I) $\cdot$ Jana Sasová $^{2} \cdot$ Ruqaia Shoheeduzzaman $^{3}$ (I) $\cdot$ Mirza T. Baig $^{3} \cdot$ Aldana Ali H. A. Alyafei $^{4} \cdot \operatorname{Jan}_{\text {Tkac }^{5}}$ (D)
}

Received: 30 September 2020 / Accepted: 19 January 2021 / Published online: 2 March 2021

(C) The Author(s) 2021

\begin{abstract}
In this study, the influence of direct electric current on a microcapsule was investigated. The microcapsule consisted of a core from a calcium ion and sodium alginate (SA) complex and the microcapsule membrane was formed by the polyionic complexation of poly(methylene-co-guanidine) (PMCG) and cellulose sulfate (CS). Microcapsules showed swelling and decreasing mechanical properties under the applied electric current, and the microcapsule membrane showed anisotropic swelling on the electrode side. The effect is attributed to an electrokinetic phenomenon, predominant formation of hydroxyl ions, and the diffusion of hydrated ions. The swelling degree of the microcapsule and microcapsule membrane at different $\mathrm{pH}$ and the applied electric current under alkali and acidic conditions was investigated. The swelling degree was influenced by the dissociation of the membrane, which was observed after applying the electric field, which was caused by the electrokinetic effect and the neutralization of the polycation (under alkali conditions) or polyanionic (under acidic conditions) segment during membrane formation.
\end{abstract}

Keywords Microcapsule $\cdot$ Alginate $\cdot$ Electrokinetic $\cdot$ Electrical field $\cdot$ Electroresponsive

\section{Introduction}

The hydrogel structure is designed as a three-dimensional cross-linked polymeric network that can absorb a large amount of water and undergo significant structural and volume changes from triggers by external stimuli [1]. These intelligent or smart hydrogel structures are highly attractive for biomedical applications, drug delivery, tissue engineering [2, 3], robotics [4, 5], and implanting artificial organs. External stimuli can modulate and tune their physical properties, like swelling or shrinking. The surface and mechanical

Peter Kasak

peter.kasak@qu.edu.qa

Jana Sasová

sasova.janka@gmail.com

Ruqaia Shoheeduzzaman rh1805547@qu.edu.qa

Mirza T. Baig

mb1706996@qu.edu.qa

Aldana Ali H. A. Alyafei aa1602359@student.qu.edu.qa

Jan Tkac

jan.tkac@savba.sk characteristics are those considered for controllable tailoring for required functions and properties. The controllable properties of smart hydrogels are tuned and intensified by changes in parameters such as $\mathrm{pH}$ [6], temperature, light, specific compounds, ions or biological species [7], and magnetic or electrical fields [8].

Recently, the application of hydrogels in electrical fields has become more attractive as the stimuli used to trigger hydrogel's characteristics can be applied in a non-invasive, timely, and spatial manner [9]. Electrical activity occurs in different types of human complexes such in neural, muscle,

1 Center for Advanced Materials, Qatar University, P.O. Box, 2713 Doha, Qatar

2 Department of Biomaterial Research, Polymer Institute, Slovak Academy of Sciences, Dubravska cesta 9, 845 41 Bratislava, Slovakia

3 College the Art and the Sciences, Qatar University, P.O. Box, 2713 Doha, Qatar

4 Chemical Engineering Department, College of Engineering, Qatar University, P.O. Box 2713, Doha, Qatar

5 Institute of Chemistry, Slovak Academy of Sciences, Dubravska cesta 9, 84538 Bratislava, Slovak Republic

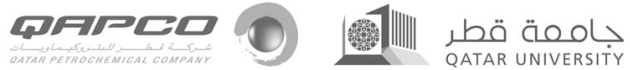


or endocrine complexes, and their artificial systems [10, 11]. The electric response is dependent on various factors that tune the degree and ability of the hydrogel to interact, such as degree of cross-linking in the hydrogel, concentration of charges in the hydrogel, voltage of the electric field, $\mathrm{pH}$, ionic strength, and the dielectric properties of the medium [12].

There are several types of electroresponsive hydrogels. The electrical-conducting nature of the hydrogels can be imparted by polymers such as intrinsically conducting polymers (ICPs), possessing high electrical conductivity, and similar electric and optical properties like metals and semiconductors; they also display common polymeric characteristics such as flexibility and easy inexpensive synthesis, for example, polyaniline (PANI) and polypyrrole (PPy). Another group of polymers that conduct through the transport of electrons between the spatially neighboring and electrostatically localized redox sites (electron hopping) are called redox polymers [13]. Other smart, electrical-field-responsive polymers are synthetic polyelectrolytes-containing polycations $[14,15]$ (for example, chitosan) or anions (for example, polyacrylic acid) given their structural composition. Nature-based hydrogels from chitosan are rarer and are still being investigated $[16,17]$.

Polyelectrolyte hydrogels in the electric field, in direct contact with cathode and anode electrodes, lead to volume collapse along with a small change in electrical potential through the hydrogel. Contrary, when hydrogel materials in solution are not in direct contact with the electrodes, the external electric field results in asymmetric swelling or shrinking related to electrodes, leading to the bending of the hydrogel [18]. Hydrogel bending is influenced by the electric field depending on the shape of the hydrogel and its distance from the electrodes $[19,20]$.

Studies on spherical hydrogel materials are rare [21]. For example, agarose spheres were least affected by the electric field compared to other gel beads like alginate and agar; hence, it lost less weight [22]. Due to its mechanical strength and neutral composition in addition to containing a large amount of water, it was able to withstand the electrical influence. The shrinking increased the mechanical strength and texture of the beads but reduced the elasticity. Conversely, the greater the osmotic pressure outside the beads, the less the effect of the electric field. Therefore, in general, shrinkage is strongly linked to electrophoresis, and the degree of shrinking can be controlled by varying the parameters. Hence, the flexibility of beads changes with their mechanical properties such that their integrity remains constant under the influence of electric field, which plays a major role in their functionality as a carrier.

Polyionic hydrogel structures, such as microcapsules or microbeads, have attracted research attention [23, 24]; one of the most commonly used representatives is microcapsules, which consist of polymers from sodium alginate (SA), cellulose sulfate (CS), poly(methylene-co-guanidine) (PMCG), and $\mathrm{Na}^{+}$and $\mathrm{Ca}^{2+}$ ions. This type of microcapsule is one of the candidates used for the treatment of diabetes as an artificial pancreas platform for Langerhans islet implantation $[25,26]$ and used as protective carriers in biotechnology $[27,28]$, cell immobilization $[29,30]$, and drug delivery $[31,32]$. The electric potential in the cell at rest is $-0.07 \mathrm{~V}$; the overall electrical potential in the human body is within the range of 103 to $107 \mathrm{mV}$. Some transformations (electroporation) [33] in biotechnology require electrical fields, and changes in $\mathrm{pH}$ occur in many biotechnological and biological processes; thus, our aim was to investigate the effects of a direct electrical field as well as the change in $\mathrm{pH}$ on polyionic-based microcapsules, namely alginate, $\mathrm{Ca}^{2+}$. based microcapsules with poly(methylene-co-guanidine), and a cellulose sulfate (CS) membrane. Therefore, the main goal of the study was to elucidate the stimuli responsiveness of PMCG-CS-alginate-based microcapsule to an electric field and $\mathrm{pH}$. Studies were conducted to analyze the effect of the electric field on the size, membrane dimension, and mechanical properties of microcapsules in solutions in non-contact with electrodes. The influence of the time of applied electrical field to the membrane of microcapsules, $\mathrm{pH}$, and subsequent applied electric current was also studied and evaluated.

\section{Experimental}

\subsection{Materials and procedure}

\subsubsection{Materials}

High-viscosity sodium alginate (SA-HV) with high mannuronic acid content (60\% of mannuronic acid units) was provided from ISP Alginates (Girvan, UK). Sodium alginate was purified using a procedure with a purification step through the organic phase. Sodium cellulose sulfate (CS) was purchased from Acros Organics (NJ, USA). Poly(methylene-co-guanidine) hydrochloride (PMCG, $35 \mathrm{wt} \%$ ) in concentrated solution in water was purchased from Scientific Polymer Products Inc. (Ontario, CA, USA). Residual formaldehyde from PMCG was removed using a freeze-drying technique. All inorganic salts, sodium chloride (CentralChem, Bratislava, Slovakia), $\mathrm{NaOH}$ (CentralChem, Bratislava, Slovakia), calcium chloride, polydimethylsiloxane (PDMS), and $\mathrm{CH}_{3} \mathrm{COOH}$ (mikroChem, Bratislava, Slovakia) were of analytical grade. Distilled, demineralized, and pyrogenic-free water (DW) was used in all experiments. 


\subsubsection{Preparation of sterile solutions for microcapsule preparation}

The polyanion (PA) solution was a mixture of SA and CS. The polycation (PC) solution consisted of polycation PMCG, $\mathrm{CaCl}_{2}$, and $\mathrm{NaCl}$. The polyanion solution was prepared by dissolving SA-HV and CS in stirred $0.9 \mathrm{wt} \% \mathrm{NaCl}$ solution. PMCG, $\mathrm{CaCl}_{2}$, and $\mathrm{NaCl}$ were dissolved in water. All solutions were prepared with ultrapure pyrogen-free water. The concentrations of individual components in PA and PC solutions and the details of the sterilization steps are summarized in Table 1.

\subsubsection{Microcapsule formation}

The PMCG microcapsules were prepared using a continuous one-step process with an air-stripping nozzle for formation of SA-CS-substance droplets and multi-loop reactor filled with PC solution, as illustrated in Fig. 1 [34]. After $40 \mathrm{~s}$ of complexation reaction, microcapsules were washed 3 times in $0.9 \mathrm{wt} \% \mathrm{NaCl}$ solution, stabilized $10 \mathrm{~min}$ in stabilization solution, and washed with $0.9 \mathrm{wt} \% \mathrm{NaCl}$ solution. The microcapsule was prepared under sterile conditions in a laminar flow cabinet. The schematic structure of the microcapsule is depicted in Fig. 1.

\subsection{Electrochemical measurements}

For measurements, we used an electrochemical cell separated by two Pt electrodes $0.7 \mathrm{~cm}$ apart, as schematically illustrated in Fig. 2, and connected to a circuit with potentiostat PAREG\&G. Platinum electrodes used as pseudo-reference and counter electrodes were flame-patterned before use. Between the electrodes, we applied physiological $0.9 \mathrm{wt} \% \mathrm{NaCl}$ solution with the measured microcapsule sample. Finally, we applied an electrical current ( 1 or $5 \mathrm{~mA}$ ) for different durations from 0 to $10 \mathrm{~min}$. The attempt we repeated 10 times for reproducibility.

From the obtained values, we found for each hydrogel the degree of swelling, which was compared with each other.
From the storage saline $(0.9 \mathrm{wt} \% \mathrm{NaCl})$, we used the necessary quantity; for $\mathrm{pH}$ adjustment, we added $0.1 \mathrm{M}$ aq. $\mathrm{NaOH}$ (pH 12.9) or $\mathrm{CH}_{3} \mathrm{COOH}(\mathrm{pH} 3.1)$.

\subsection{Characterization}

\subsubsection{Optical microscopy}

The size of the microcapsules and membrane thickness were estimated using optical microscopy, which consisted of an optical microscope (Kapa 2000, Slovakia) equipped with a color CCD camera (Mintron CC-63KW1P, Malaysia) and Prover Image Forge v1.1 software, tailor-designed for microcapsule optical microscopy (Prover s.r.o., Slovakia). Twentyfive microcapsules or microbeads per batch were randomly selected to determine the average size and membrane thickness.

\subsubsection{Mechanical characterization}

Microcapsules were tested on a Texture Analyzer TA-2Xi (Stable Micro Systems, Godalming, UK), and Texture Expert version 1.16 software was used for determination. The equipment consisted of a mobile probe moving vertically downward at a constant velocity of $0.5 \mathrm{~mm} / \mathrm{s}$. Each measurement was recorded on an individual microcapsule that was removed after a certain time from the reaction cell. The microcapsules were placed in $0.9 \mathrm{wt} \% \mathrm{NaCl}$ storage solution. The microcapsule had an average size of $0.65-0.75 \mathrm{~mm}$ in diameter and was compressed until bursting occurred. The force, expressed in grams, was recorded as a function of the compression distance. Twenty-five microcapsules per batch were analyzed to obtain relevant data.

\subsubsection{Fourier transform infrared-attenuated total reflection}

FTIR spectra were obtained on a Nicolet TM 6700 spectrometer in the middle infrared (MIR) region $\left(4000-400 \mathrm{~cm}^{-1}\right)$. For each sample, 128 scans with a resolution of $4 \mathrm{~cm}^{-1}$ were recorded. Spectra were evaluated using the OMNIC 8.0 software package (Nicolet Instruments Corp.).

Table 1 Detailed information of solutions used for microcapsule formation. $P A$, polyanion; $P C$, polycation; $S A$, sodium alginate; $C S$, cellulose sulfate; $P M C G$, poly(methylene-co-guanidine)

Encapsulation solutions

PA solution

Sterilization

PC solution

Stabilization solution

Other materials
$1.0 \% \mathrm{SA}-\mathrm{HV}+1.0 \% \mathrm{CS}$ diluted in $0.9 \% \mathrm{NaCl}, \mathrm{pH} 7.03$

Syringe $0.45-\mu \mathrm{m}$ GF filter (Agilent Technologies, USA) and sterile $0.22-\mu \mathrm{m}$ filter (TPP, Switzerland) $1.2 \% \mathrm{PMCG}, 1.3 \% \mathrm{CaCl}_{2}, 0.9 \% \mathrm{NaCl}$ in ultrapure pyrogen-free water, $\mathrm{pH} 7.11$

$0.11 \mathrm{wt} \% \mathrm{CS}$ vs. $100 \mathrm{~mL} 0.9 \% \mathrm{NaCl}(\mathrm{pH}=7.25)$

$0.9 \% \mathrm{NaCl}$ solution, $\mathrm{pH} 7.4$ 
Fig. 1 Schematic presentation of microcapsule formation (upper) and microcapsule (lower)
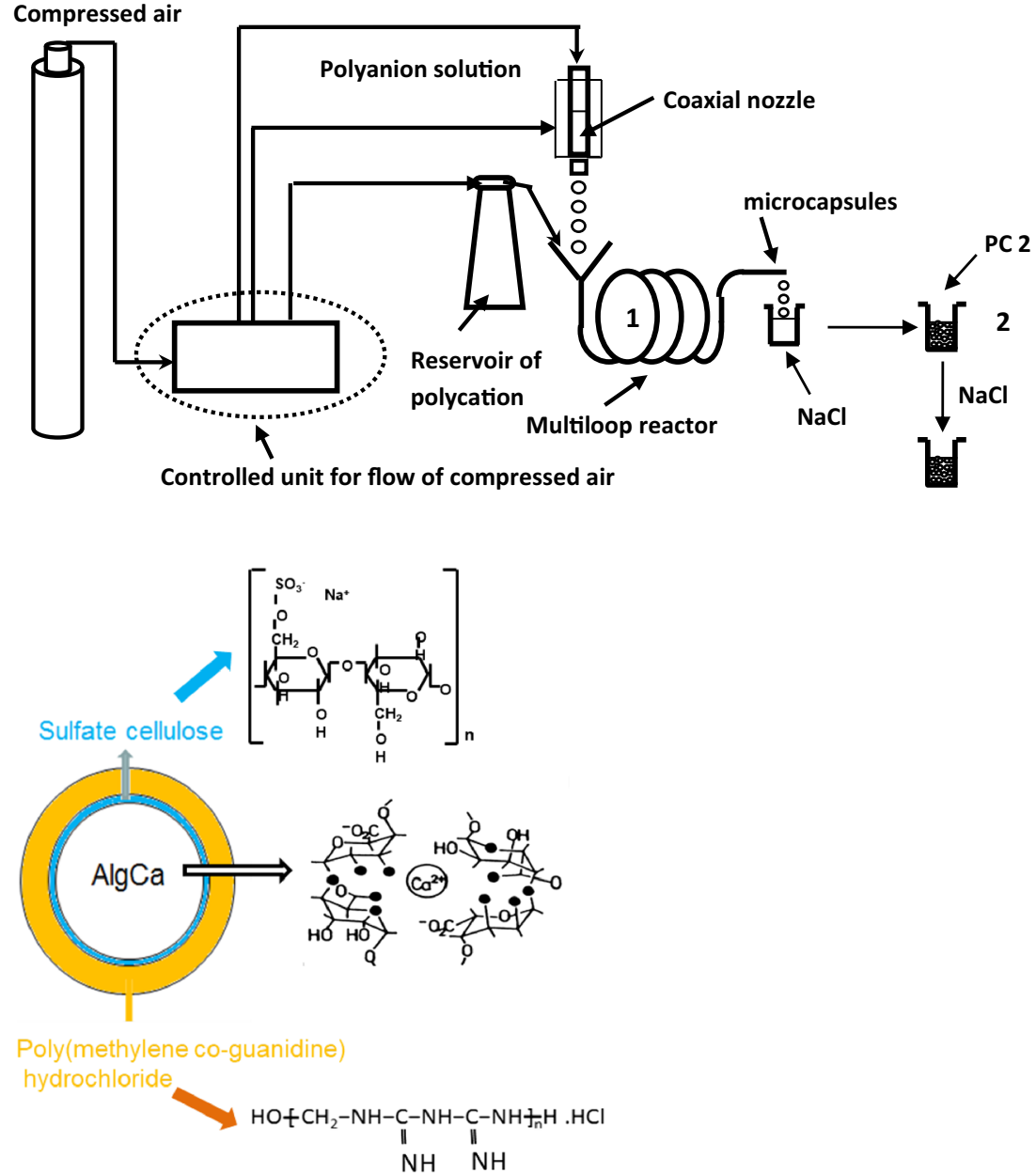

To monitor microcapsules in the IR region, we used the ATR technique. We measured the lyophilized microcapsules before and after the application of electric current.

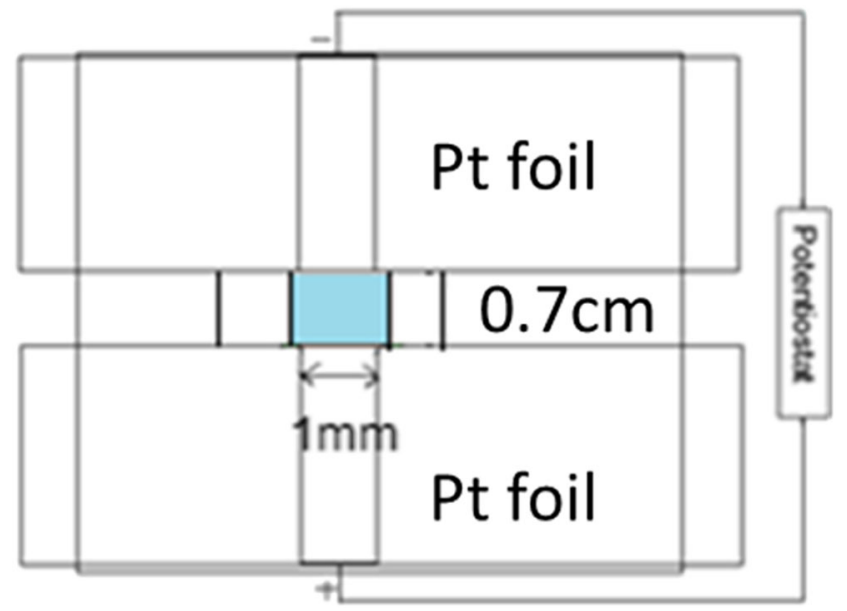

Fig. 2 Electrochemical cell for monitoring the microcapsules in an electric field

\section{Results and discussion}

\subsection{Microcapsule in direct electric field}

Pt electrodes were used and the distance between electrodes was adjusted to $7 \mathrm{~mm}$. At $20 \mathrm{~mm}$, we did not observe visual changes in the microcapsules, membrane size, or permeation. The distance between electrodes was adjusted to $7 \mathrm{~mm}$ in $0.14 \mathrm{~mL}$ physiological $0.9 \% \mathrm{NaCl}$ solution. At the large distance of $20 \mathrm{~mm}$ and volume of $2 \mathrm{~mL}$, we observed changes were slower and swelling occurred at a lower rate. The microcapsule consisted of a core that is stable due to alginate- $\mathrm{Ca}^{2+}$ complexation; the membrane was formed by polyionic complexation from polycation polymer (PMCG) and polyanions CS and SA. The size of the microcapsules ranged from 650 to $760 \mu \mathrm{m}$ and the thickness of membrane was 50 to $70 \mu \mathrm{m}$.

In neutral $\mathrm{pH}(7.03)$ and physiological $0.9 \mathrm{wt} \% \mathrm{NaCl}$ solution after the application of electric field, the microcapsule began to deform and swell (Figs. 3 and 4). The formula used for calculating the swelling degree was as follows: 
Fig. 3 Microscopic image of microcapsule during experiments in a direct electric field: a 60 , b 180 , c 360 , d 480 , and e 540 s. $I=$ $1 \mathrm{~mA}$ in $0.14 \mathrm{~mL} 0.9 \%$ aq. $\mathrm{NaCl}$; cathode side left and anode side right for all in images
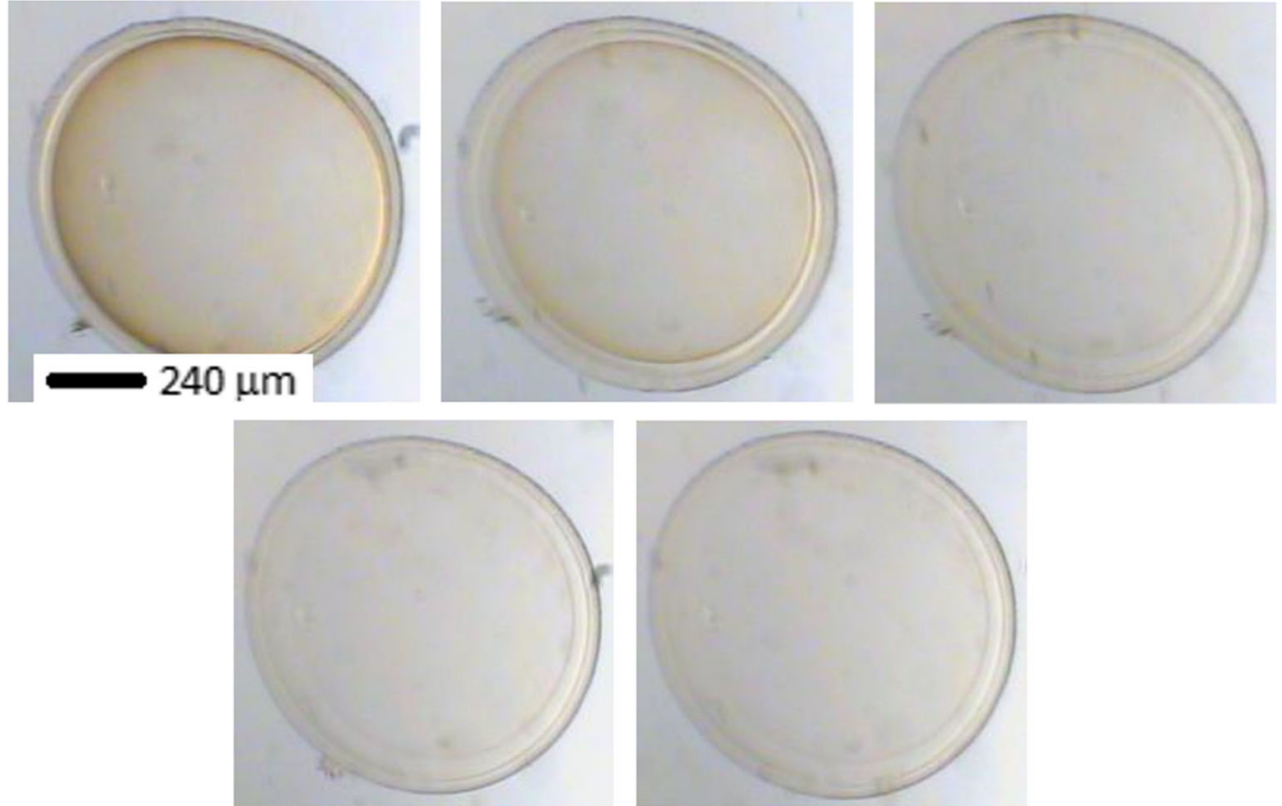

Swelling degree $=\frac{\text { Size of material after time-Size of material on beginning of experiment }}{\text { Size of material on beginning of experiment }} \times 100(\%)$

In the microcapsule swelling experiment, four different aspects of microcapsule swelling were considered. The change of ovality of microcapsule samples was negligible and within $2 \%$, indicating that the microcapsules' core, as the main component of the microcapsules, was changing homogenously in whole volume. Upon initial exposure to $1 \mathrm{~mA}$ DC electric current, the hydrogels appeared to shrink in size by decreases in the degree of swelling to $2 \%$ during the first $2 \mathrm{~min}$, after which it increased steadily in size with time, reaching a maximum swelling degree of $10 \%$ in size at $10 \mathrm{~min}$. However, at the higher current of $5 \mathrm{~mA}$, the microcapsule appeared to shrink initially by $1 \%$ and began increasing from $3 \mathrm{~min}$ onward, after which it followed a trend similar to the swelling behavior observed at the cathode; that is, the size increased at a steady rate up to a maximum of $15 \%$ at $10 \mathrm{~min}$. Compared to the hydrogel membranes at the cathode, the membranes at the anode increased linearly and were more swollen, by $5 \%$.

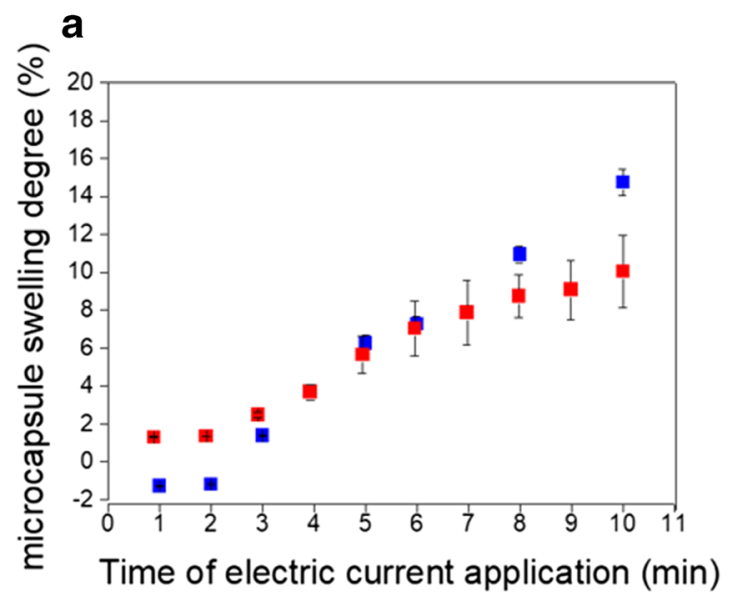

b

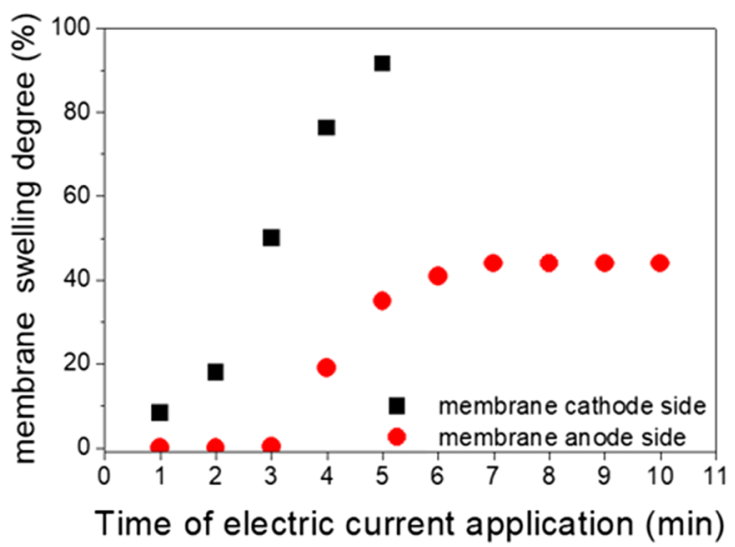

Fig. 4 a Swelling degree of microcapsules under $1 \mathrm{~mA}$ (red square) and $5 \mathrm{~mA}$ (blue square) electric current. b Swelling degree of microcapsule membranes at cathode (black) and anode (red) sides under $1 \mathrm{~mA}$ electric current 
Anisotropic swelling was observed in the size of membranes (Figs. 3 and $4 \mathrm{~b}$ ). The membrane did not undergo shrinkage initially and began expanding on the cathode side after $1 \mathrm{~min}$ to $4 \%$, and continued until $5 \mathrm{~min}$ to $100 \%$; no other changes were observed by the end of the experiments. On the anode side, a slower increase in the initial $3 \mathrm{~min}$ was observed and the swelling degree rose at $3 \mathrm{~min}$ to $4 \%$ and continued to reach the maximum at $7 \mathrm{~min}$, with a swelling degree up to $40 \%$ at the cathode side. This swelling degree remained until the end of the experiments. In the microcapsule, the $\mathrm{Ca}^{2+}$ ions, as a crosslinker agent in the egg box structure and possibly the formed $\mathrm{H}_{3} \mathrm{O}^{+}$ions, migrated toward the cathode side [35] and the water from the solution entered the alginate gels. This led to the decrease in the $\mathrm{Ca}^{2+}$-occupied side in $\mathrm{SA}-\mathrm{Ca}^{2+}$ egg box complexes. The movement of these ions and polyions under direct electric current promoted anisotropic behavior in the membrane swelling, as shown in Fig. 1b. Anisotropic swelling on the different sides of the electrochemical cell can be attributed to electrokinetic contractive phenomenon [36] due to the migration of water and the charged opposite ions in relation to polyelectrolytes in systems [37, 38].

Anisotropic behavior was observed for the membrane near the anode and cathode side. Under the influence of electricity, mobile $\mathrm{H}^{+}$ions move toward the negatively charged cathode, whereas the anode attracts negatively charged $\mathrm{OH}^{-}$groups and active carboxylate and sulfate groups occurring in the network of the polymers. This results in differences in swelling at the anode side. Simultaneously, a uniaxial stress forms within the axis of the hydrogel matrices due to the electrostatic force of attraction between the negatively charged SA, PMCG, and CS groups and the anode [39, 40]. The movement of both the polyanionic carboxylic groups to the anode and polycationic carboxylic groups to the cathode creates uniaxial stress on the microcapsule due to electrostatic interaction at the electrode causing swelling changes in the hydrogel membrane. Anisotropic behavior is mostly visible in the membrane as the core of the microcapsule sustains the spherical shape.
This is attributed to the self-healable, dynamic, and strong non-covalent complexation driven by the formation of $\mathrm{Ca}^{2+}$ and alginate; this behavior is similar to that of planar SA complexes with $\mathrm{Ca}$ ions [41].

The mechanical properties measurement results are provided in Fig. 5a. The mechanical properties were measured in compression mode of single individual microcapsules following an established technique [42], and an arbitrarily force value of $60 \%$ microcapsule deformation was selected as indicator of the change in mechanical properties. We observed a decrease in force over time, indicating the loss of integrity of the microcapsules. The force at $60 \%$ deformation started at $3.6 \mathrm{~g}$ and continually decreased to $0.7 \mathrm{~g}$ for microcapsules after 10 min under the applied electric current. The loss of microcapsule integrity is mainly attributed to retraction of the eggbox complex of bidentate $\mathrm{Ca}^{2+}$ ions and alginate [43]. This observation indicated that $\mathrm{Ca}^{2+}$ ions in the electrical field migrate from the microcapsule core to the microcapsule shell, which causes mechanical properties to continually decline. Pt electrodes might form hydroxyl anions after the hydrogen evolution reaction-cathode side. Subsequently, the ion $\left(\mathrm{Ca}^{2+}\right)$ bound to the $\mathrm{COO}^{-}$group from the egg box reacts with $\mathrm{OH}^{-}$ions, probably leading to the formation of $\mathrm{Ca}(\mathrm{OH})_{2}$, which, in the presence of $\mathrm{CO}_{2}$ contained in the air, turns into $\mathrm{CaCO}_{3}$ and $\mathrm{H}_{2} \mathrm{O}$. Subsequently, $\mathrm{Ca}^{2+}$ ions are substituted by $\mathrm{Na}^{+}$.

Migration of $\mathrm{Ca}^{2+}$ ions and leaking of microcapsules was also supported by AAS techniques. The storage solution from the microcapsules contained $0.65 \mathrm{mg} / \mathrm{L}$ calcium ions, which was measured in the solution after $10 \mathrm{~min}$ in an electric field, which led to the increase in $\mathrm{Ca}^{2+}$ ions to $1 \mathrm{mg} / \mathrm{L}$.

The electrochemical reaction might lead to the formation of predominantly basic species; as such, $\mathrm{pH}$ was monitored throughout the reaction (Fig. 5b). The initial $\mathrm{pH}$ readings were neutral, remaining at 7.3 for the first $2 \mathrm{~min}$. However, at $3 \mathrm{~min}$, a spike in $\mathrm{pH}$ was observed, rising from 7.5 to 11 , indicating that the reactions were strongly basic in nature. From $3 \mathrm{~min}$ a

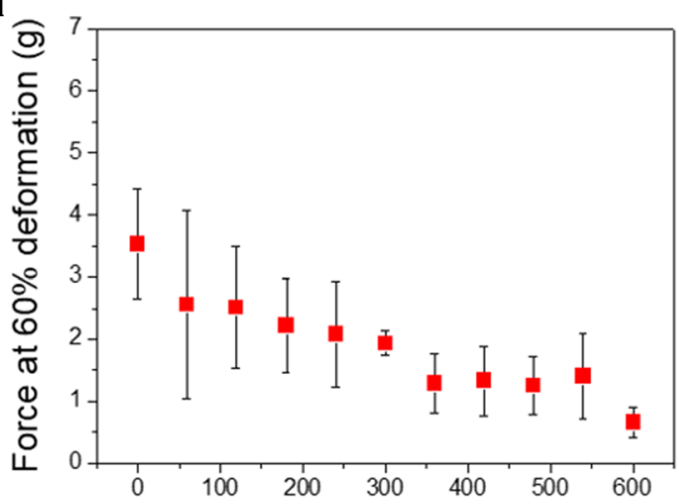

b

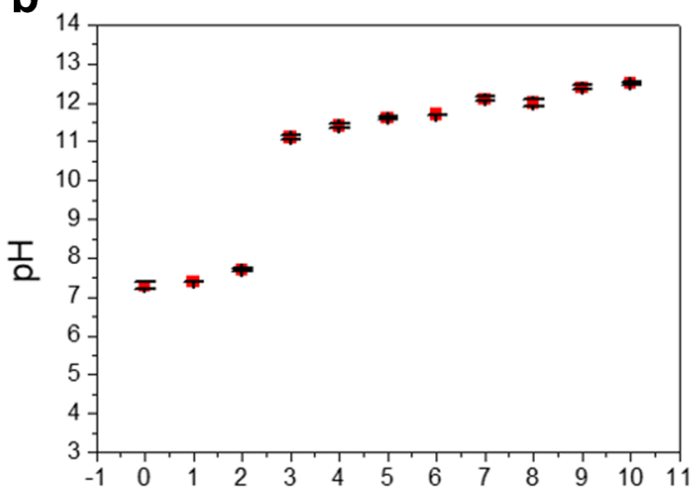

Time of electric current application (min)

Time of electric current application (min)

Fig. 5 a Force during compression test to $60 \%$ deformation of the microcapsule under $1 \mathrm{~mA}$. b pH solution during applied electric current 
onward, the $\mathrm{pH}$ increased gradually to a maximum of 12.5 at $10 \mathrm{~min}$.

This indicated that hydroxyl ions that are formed in the electrochemical reaction were responsible for changing one of the main factors: swelling behavior. We assumed that hydroxyl anion is formed on the cathode side from hydrogen evolution reaction (HER) and such hydroxyl ion is migrated to the microcapsule toward the cathode and react as it is discussed above and the anode side is forming oxygen together with transformation of hydroxyl ions to form oxygen and water molecules as is summarized.

$$
\begin{aligned}
& \text { Cathode reaction : } 4 \mathrm{H}_{2} \mathrm{O}+4 \mathrm{e}^{-} \rightarrow 2 \mathrm{H}_{2}+4 \mathrm{OH}^{-} \\
& \text {Anode reaction : } 4 \mathrm{OH}^{-} \rightarrow 2 \mathrm{H}_{2} \mathrm{O}+\mathrm{O}_{2}+\mathrm{e}^{-}
\end{aligned}
$$

We observed progress of changes of $\mathrm{pH}$ to higher values was demonstrated by applying of $\mathrm{pH}$ indicator (phenyl red) to reaction cell in the initial $3 \mathrm{~min}$ as is depicted in Fig. 6a. In the beginning of the experiment, $\mathrm{pH}$ value was 7 in whole cell. After application of electric current, $\mathrm{pH}$ after 1 min started to change form side of cathode and progressively changed to whole reaction cell after $3 \mathrm{~min}$. Additionally, gas formation was observed and if electrodes were changed to $\mathrm{Al}$ electrode then $\mathrm{Al}(\mathrm{OH})_{3}$ as white precipitate was formed (Fig. 6b). Such precipitate strongly influences microcapsules during measurement and deforms them with high level of ovality. It should be mentioned that during analysis relatively high potential up to $4 \mathrm{~V}$ was observed as is depicted in Fig. 6c and such potential is sufficient for water splitting reaction (Fig. 6c).

Fourier transform infrared-attenuated total reflection (FTIR-ATR) microscopy was used to obtain information about the chemical characteristics of some main individual functional groups of lyophilized microcapsules (Fig. 7). FTIR spectra in the mid-infrared region $\left(4000-600 \mathrm{~cm}^{-1}\right.$, Fig. 7 upper) showed strong hydrogen bonding stretching vibration in the $3000-3500 \mathrm{~cm}^{-1}$ region and $\mathrm{C}-\mathrm{H}$ stretching absorption at $2800-3000 \mathrm{~cm}^{-1}$ for both samples [44]. The sample, before application of the electric field in terms of hydrogen stretching vibration, showed a broad absorption peak with maximum at $3300 \mathrm{~cm}^{-1}$. The sample after application of the electric field showed a higher absorption peak, with a maximum at about $3450 \mathrm{~cm}^{-1}$, with a narrower profile, indicating less hydrogen bonding compared to an unmodified sample. The enlarged FTIR region at $1800-700 \mathrm{~cm}^{-1}$ is depicted in Fig. 7 (lower). In the unmodified sample, we observed main absorption peaks at 1606 and $1410 \mathrm{~cm}^{-1}$ for asymmetric and symmetric $\mathrm{COO}^{-}$stretching vibration, respectively, and at about $1023 \mathrm{~cm}^{-1}$ for $\mathrm{C}-\mathrm{O}$ stretching vibration, attributed to the alginate component. The PMCG component was confirmed by $\mathrm{C}-\mathrm{N}$ bending vibration at $1523 \mathrm{~cm}^{-1}$. The absorption peaks at 1236, 1190, and $1020 \mathrm{~cm}^{-1}$ are attributed to asymmetric and symmetric $\mathrm{SO}_{2}$ and $\mathrm{C}-\mathrm{O}$ stretching vibration, respectively, in the CS component. The main difference in the sample after applying the electric field was the asymmetric $\mathrm{COO}^{-}$stretching from the SA segment, which shifted to an absorption peak maxima at $1620 \mathrm{~cm}^{-1}$. This observation also showed the trend in the hydrogen stretching region, indicating that $\mathrm{C}=\mathrm{O}$ bound from the alginate segment has higher strength and provides fewer hydrogen bonding interactions. These results indicated less interaction of the carboxylate group from alginate segment with the system, which agrees with and supports previous observation and analysis.
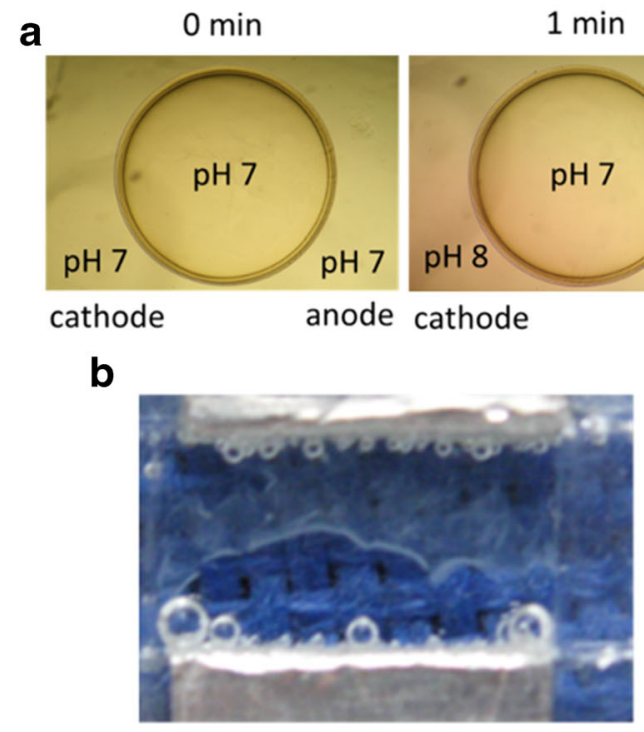

$1 \mathrm{~min}$

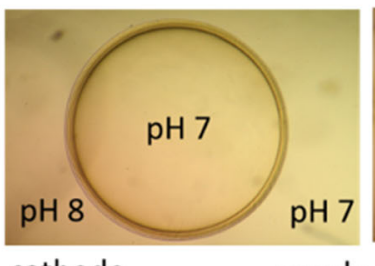

$2 \min$

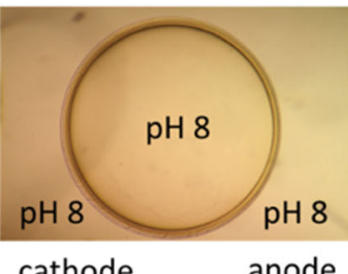

$3 \mathrm{~min}$

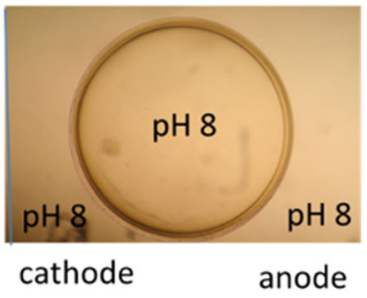

C

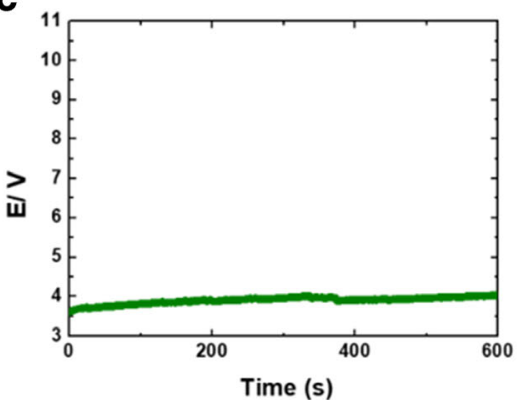

Fig. 6 a Experiment with $\mathrm{pH}$ indicator (phenyl red) in reaction cell with microcapsule. b Gas evolution and precipitation formation in reaction cell with Al electrode. c Electric potential in reaction cell under $1 \mathrm{~mA}$ 


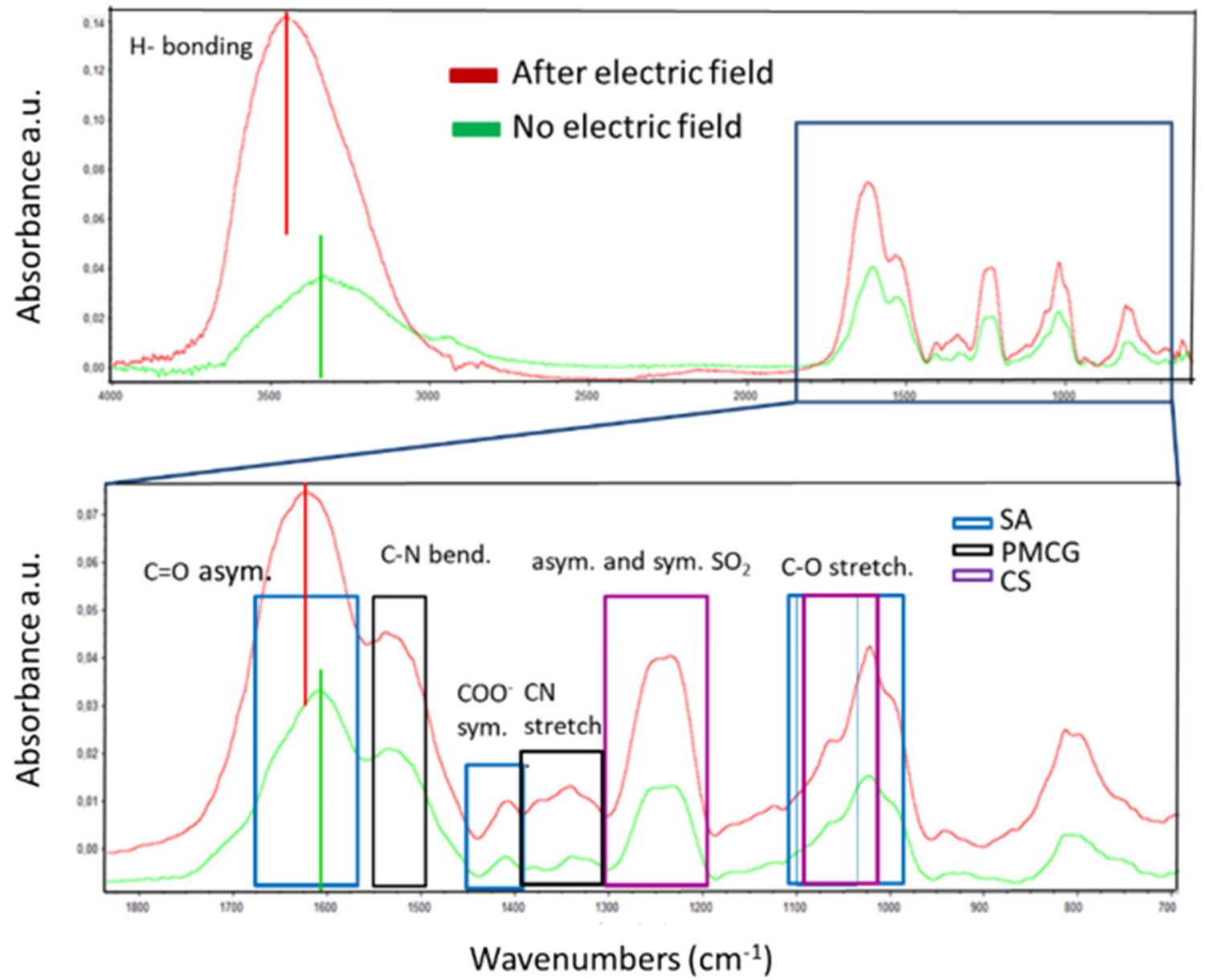

Fig. 7 FTIR spectra of lyophilized microcapsules: before (green) and after (red) application of 10 min of electric current

\subsection{Effect of DC electric field on microcapsule at different $\mathrm{pH}$}

\subsubsection{Effect of $\mathrm{pH}$ on microcapsules}

As mentioned in Section 1, microcapsules are intended for various biotechnology and biomedical applications. Such processes often involve dramatic changes in environmental $\mathrm{pH}$. Therefore, we further examined the effect of the direct electric current on the microcapsule at different $\mathrm{pH}$. The first microcapsules were incubated in basic $12.3 \mathrm{pH}$ (adjusted with $\mathrm{NaOH}$ ) and acidic $3.1 \mathrm{pH}$ (adjusted with acetic acid) solutions, and the observed effect on swelling degree in relation to $\mathrm{pH}$ is summarized in Fig. 8. a

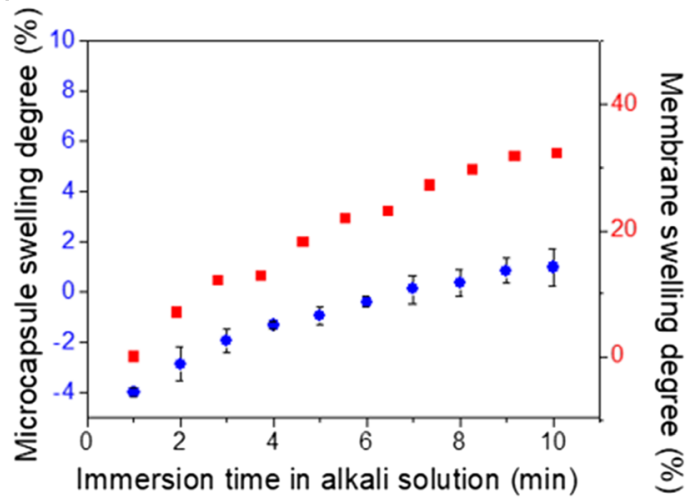

b

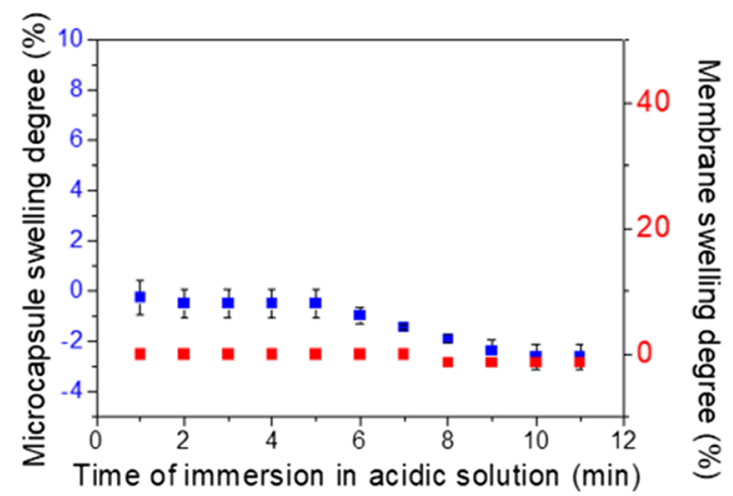

Fig. 8 Swelling degree of the microcapsule (blue square, left $y$-axis) and membrane (red square, right $y$-axis) after immersion in a alkaline and $\mathbf{b}$ acidic media 

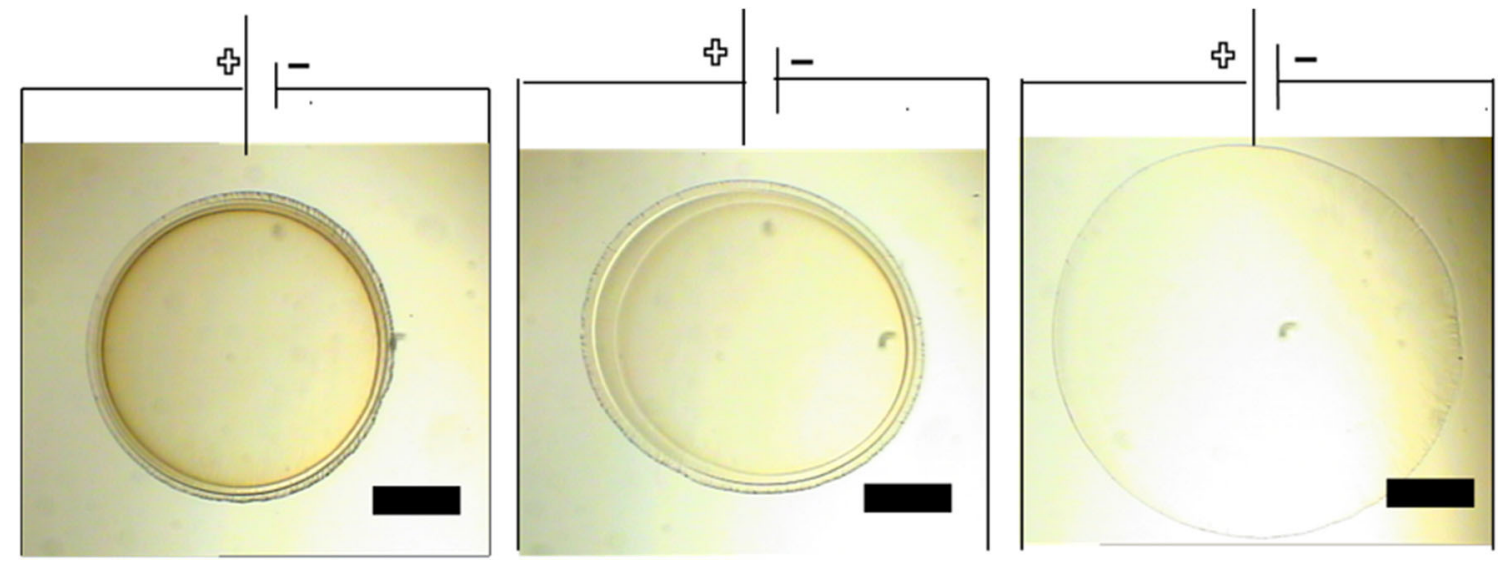

Fig. 9 Microscopic image of microcapsule after 1, 4, and $10 \mathrm{~min}$ in an alkali solution

At first in the alkaline solution, the microcapsule shrunk by $4 \%$, probably due to the positively charged PMCG group (Fig. 8a). However, after a certain time, the ions moved to the core of the microcapsules from the solution, causing the microcapsule to swell. The degree of swelling was $1 \%$. The membrane in alkaline solution also swelled by $20 \%$.

In the acidic medium, the hydrogel at $6 \mathrm{~min}$ began to shrink; the contraction stabilized in acid solution after 9 min with a swelling degree of $-3 \%$. (Fig. 8b). The membrane appeared to be stable in an acid medium and no change was observed. Swelling and shrinking in alkaline and acidic solution, respectively, is in agreement with observation to $\mathrm{Ca}^{2+}$ SA complex reported previously caused by electrostatic repulsion between polyanions and dissociation of ions and polyions at different $\mathrm{pH}$ in microcapsules.

Similar to the effect under an electrical field due to the presence of $\mathrm{OH}-$ in an alkaline medium, the $\mathrm{Ca}^{2+}$ ions transform into insoluble $\mathrm{CaCO}_{3}$ and $\mathrm{H}_{2} \mathrm{O}$. Under acidic conditions, the carboxylate anion of alginate converts to a carboxylic acid group after the addition of $\mathrm{H}^{+}$in the fluid, becoming largely undissociated. The carboxyl groups in this state are much less hydrated, and the gel can consequently contract.

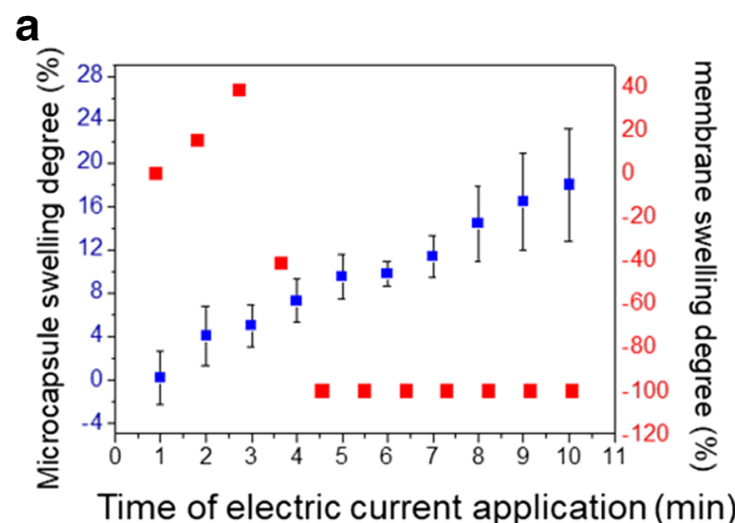

The alginate is negatively charged. We confirmed that the microcapsule shrinks in acidic media and swells in alkaline media.

\subsubsection{Effect of $\mathrm{pH}$ on microcapsule under electric current}

The swelling degree of the microcapsule and membrane in an alkali solution is depicted in Figs. 9 and 10a. The samples under electric current swelled steadily from $0 \%$ at $1 \mathrm{~min}$ to $18 \%$ at $10 \mathrm{~min}$. This trend was also attributed to the electrokinetic effect and presence of dissociated $\mathrm{OH}^{-}$, as discussed previously. The membranes, however, exhibited dramatic swelling initially; at $1 \mathrm{~min}$, the swelling increased to $20 \%$ and rose to a maximum of $40 \%$ at $2 \mathrm{~min}$. The swelling decreased dramatically to $-40 \%$ at $3 \mathrm{~min}$, which further decreased $-100 \%$ at $4 \mathrm{~min}$, after which a constant state was achieved. In the alkali solution, the presence of $\mathrm{OH}^{-}$ions and subsequent faster mobility due to the electric field promoted the neutralization of the PMCG component from the quaternary charge state to the charged-balance guanidine state. This led to the decrease in polyionic complexation in the membrane structure and to the faster dissociation of the

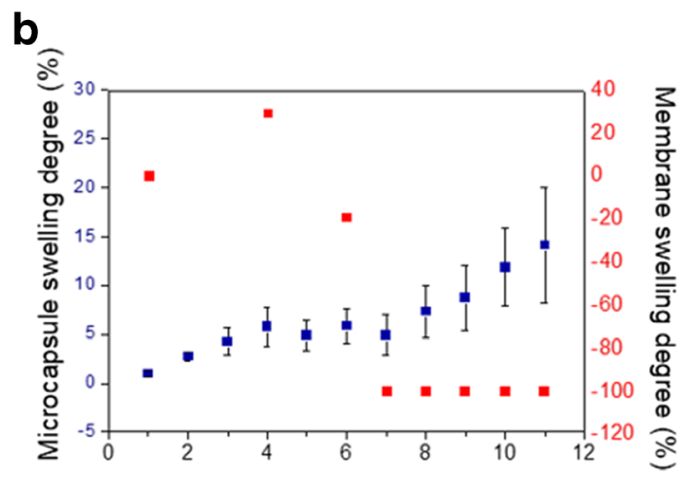

Time of electric current application (min)

Fig. 10 Swelling degree of the microcapsule (blue square, left $y$-axis) and membrane (red square, right $y$-axis) under electric current under a alkaline and b acidic conditions and an electric current of $5 \mathrm{~mA}$ 
membrane. This dissociation of complexes was also observed in chitosan tripolyphosphate complexes [45].

The control microcapsule sample changed in size over the course of the experiment at a steady rate. Compared to the control group of hydrogels that shrunk at $1 \mathrm{~min}-4 \%$ and increased steadily to a maximum of $0.4 \%$, the experimental group showed substantial changes in size. At $10 \mathrm{~min}$, the control group of hydrogels showed a maximum swelling of $2 \%$.

The experiment was also carried out under acidic conditions to test the effect of the electric current on the degree of swelling in hydrogel microcapsules and membranes when exposed to an electric field and to examine the status of the $\mathrm{pH}$, as shown in Fig. 10b. At $1 \mathrm{~min}$, the hydrogels exposed to electricity remained at $0 \%$ and increased $5 \%$ in $4 \mathrm{~min}$. The maximum swelling observed was at $12 \mathrm{~min}$, at which point the hydrogels swelled by $12 \%$. The membranes swelled to a maximum of $30 \%$ after $4 \mathrm{~min}$ of exposure to the DC electric current. At $6 \mathrm{~min}$, they changed to $-20 \%$ of their size, after which they maintained a constant shrinking.

The $\mathrm{pH}$ of the solution during the electrochemical reactions increased from the starting point of 3.5 (highly acidic) at $0 \mathrm{~min}$ to a maximum of 8 (neutral or weakly basic). A small increase in $\mathrm{pH}$ was observed from 6 at $8 \mathrm{~min}$ to 7.8 at $9 \mathrm{~min}$.

\section{Conclusion}

We examined and evaluated the effect of an applied direct electric current at different $\mathrm{pH}$ to microcapsules consisting of a core from a Ca-SA complex and a membrane formed with a polyionic complex of CS and PMCG. In neutral solution, the microcapsule swelled under the electric field, which consequently led to the decrease in its mechanical properties. The microcapsule membrane swelled anisotropically and initially swelled from the cathode side due to the diffusion of $\mathrm{OH}^{-}$ions and the electrokinetic effect. The microcapsule and the membrane are $\mathrm{pH}$-sensitive, which is attributed to changes in the electrostatic repulsion interaction of the segments of the microcapsule. Applying an electric current in alkali and acidic solutions led to higher degree of swelling and dissociation of the membrane due to the electrokinetic effect and the neutralization of polycation (in alkali condition) or polyanionic (in acidic condition) segments in the membrane. The individual microcapsules changed up to $14 \%$ in diameter, which is a significant difference, especially considering that microcapsules are applied in large quantities so may dramatically change volume. The change in mechanical properties can significantly influence the biocompatibility and processability of materials. Studying the effect of electrical fields and $\mathrm{pH}$ not only provides control and tunable material properties but also elucidates the response of microcapsules and hydrogels to electric field and $\mathrm{pH}$, which can be applied in biotechnological process requiring electrochemical reaction [46], smart robotics [47], energy production [48], and water separation processes [49].

Acknowledgements The authors thank Dr. Gabriela Hlouskova, Polymer Institute, SAS, Bratislava, Slovakia, for support with microcapsule preparation and characterization; Prof. Igor Lacik, Polymer Institute, SAS, Bratislava, Slovakia, for generously providing laboratory facilities; and Dr. Marek Bujdos, Geological Institute, Comenius University, Bratislava, Slovakia, for support with AAS analysis.

Funding Open access funding provided by the Qatar National Library. This publication was supported by Qatar University Grant IRCC-2020004 .

\section{Declarations}

Conflict of interest The authors declare no conflict of interest.

Disclaimer The statements herein are solely the responsibility of the authors.

Open Access This article is licensed under a Creative Commons Attribution 4.0 International License, which permits use, sharing, adaptation, distribution and reproduction in any medium or format, as long as you give appropriate credit to the original author(s) and the source, provide a link to the Creative Commons licence, and indicate if changes were made. The images or other third party material in this article are included in the article's Creative Commons licence, unless indicated otherwise in a credit line to the material. If material is not included in the article's Creative Commons licence and your intended use is not permitted by statutory regulation or exceeds the permitted use, you will need to obtain permission directly from the copyright holder. To view a copy of this licence, visit http://creativecommons.org/licenses/by/4.0/.

\section{References}

1. X. Liu, J. Liu, S. Lin, X. Zhao, Mater. Today 36, 102 (2020)

2. N.N. Ferreira, L.M.B. Ferreira, V.M.O. Cardoso, F.I. Boni, A.L.R. Souza, M.P.D. Gremião, Eur. Polym. J. 99, 117 (2018)

3. A.S. Theus, M.L. Tomov, A. Cetnar, B. Lima, J. Nish, K. McCoy, M. Mahmoudi, V. Serpooshan, Emergent Mater. 2, 193 (2019)

4. M. Wehner, R.L. Truby, D.J. Fitzgerald, B. Mosadegh, G.M. Whitesides, J.A. Lewis, R.J. Wood, Nature 536, 451 (2016)

5. D. Rus, M.T. Tolley, Nature 521, 467 (2015)

6. J. Liu, Y. Pang, S. Zhang, C. Cleveland, X. Yin, L. Booth, J. Lin, Y.L. Lee, H. Mazdiyasni, S. Saxton, A.R. Kirtane, T.V. Erlach, J. Rogner, R. Langer, G. Traverso, Nat. Commun. 8, 124 (2017)

7. N. Rauner, M. Meuris, M. Zoric, J.C. Tiller, Nature 543, 407 (2017)

8. S.H. Yuk, S.H. Cho, H.B. Lee, Pharm. Res. 9, 955 (1992)

9. I. Ali, L. Xudong, C. Xiaoqing, J. Zhiwei, M. Pervaiz, Y. Weimin, L. Haoyi, M. Sain, Mater. Sci. Eng. C 103, 109852 (2019)

10. H. Yuk, B. Lu, X. Zhao, Chem. Soc. Rev. 48, 1642 (2019)

11. H.C. Lai, L.Y. Jan, Nat. Rev. Neurosci. 7, 548 (2006)

12. M.C. Koetting, J.T. Peters, S.D. Steichen, N.A. Peppas, Mater. Sci. Eng. R. Rep. 93, 1 (2015)

13. M. Tomczykowa, M.E. Plonska-Brzezinska, Polymers 11, 350 (2019)

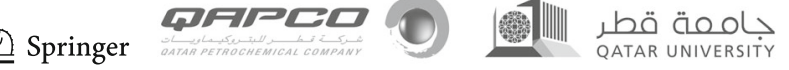


14. V. Sénéchal, H. Saadaoui, J. Rodriguez-Hernandez, C. Drummond, Faraday Discuss. 199, 335 (2017)

15. D.D. Rossi, M. Suzuki, Y. Osada, P. Morasso, J. Intell. Mater. Syst. Struct. 3, 75 (1992)

16. R. Tomer, D. Dimitrijevic, A.T. Florence, J. Control. Release 33, 405 (1995)

17. J.D. Willott, T.J. Murdoch, G.B. Webber, E.J. Wanless, Prog. Polym. Sci. 64, 52 (2017)

18. H. Li, R. Luo, K.Y. Lam, J. Membr. Sci. 289, 284 (2007)

19. T. Wallmersperger, A. Attaran, K. Keller, J. Brummund, M. Guenther, G. Gerlach, Modeling and Simulation of Hydrogels for the Application as Bending Actuators. Progr. Colloid Polym. Sci., 189-204 (2013)

20. J.P. Gong, N. Komatsu, T. Nitta, Y. Osada, J. Phys. Chem. B 101, 740 (1997)

21. J.M. Korde, B. Kandasubramanian, Ind. Eng. Chem. Res. 58, 9709 (2019)

22. R. Zvitov, A. Nussinovitch, Food Hydrocoll. 15, 33 (2001)

23. A. Renken, D. Hunkeler, J. Microencapsul. 24, 20 (2007)

24. A.M. Rokstad, O. Brekke, B. Steinkjer, L. Ryan, G. Kolláriková, B.L. Strand, G. Skjåk-Bræk, I. Lacík, T. Espevik, T.E. Mollness, Acta Biomater. 7, 2566 (2011)

25. M. Qi, J. Mcgarrigle, Y. Wang, E. Marchese, M. Bochenek, P. Vaca, M. Davis, S. Ahn, A. Schwartz, B. Strand, I. Lacik, J. Oberhozier, Micro Nanosyst. 5, 186 (2013)

26. M.A. Bochenek, O. Veiseh, A.J. Vegas, J.J. McGarrigle, M. Qi, E. Marchese, M. Omami, J.C. Doloff, J. Mendoza-Elias, M. Nourmohammadzadeh, A. Khan, C. Yeh, Y. Xing, D. Isa, S. Ghani, J. Li, C. Landry, A.R. Bader, K. Olejnik, M. Chen, J. Hollister-Lock, Y. Wang, D.L. Greiner, G.C. Weir, B.L. Strand, A.M.A. Rokstad, I. Lacik, R. Langer, D.G. Anderson, J. Oberholzer, Nat. Biomed. Eng. 2, 810 (2018)

27. M. Polakovič, J. Švitel, M. Bučko, J. Filip, V. Neděla, M.B. Ansorge-Schumacher, P. Gemeiner, Biotechnol. Lett. 39, 667 (2017)

28. A. Schenkmayerová, M. Bučko, P. Gemeiner, D. Trel’ová, I. Lacík, D. Chorvát, P. Ačai, M. Polakovič, L. Lipták, M. Rebroš, M. Rosenberg, V. Štefuca, V. Neděla, E. Tihlaříková, Appl. Biochem. Biotechnol. 174, 1834 (2014)
29. P.D. Vos, H.A. Lazarjani, D. Poncelet, M.M. Faas, Adv. Drug Deliv. Rev. 67-68, 15 (2014)

30. X. Huang, X. Zhang, X. Wang, C. Wang, B. Tang, J. Biosci. Bioeng. 114, 1 (2012)

31. M. Takacova, G. Hlouskova, M. Zatovicova, M. Benej, O. Sedlakova, J. Kopacek, J. Pastorek, I. Lacik, S. Pastorekova, J. Enzyme Inhib. Med. Chem. 31, 110 (2016)

32. P.D. Vos, M. Bučko, P. Gemeiner, M. Navrátil, J. Švitel, M. Faas, B.L. Strand, G. Skjak-Braek, Y.A. Morch, A. Vikartovská, Biomaterials 30, 2559 (2009)

33. T. Kotnik, W. Frey, M. Sack, S.H. Meglič, M. Peterka, D. Miklavčič, Trends Biotechnol. 33, 480 (2015)

34. A.V. Anilkumar, I. Lacik, T.G. Wang, Biotechnol. Bioeng. 581, 75 (2001)

35. Y. Qiu, K. Park, Adv. Drug Deliv. Rev. 321, 53 (2001)

36. T. Budtova, I. Suleimenov, S. Frenkel, Polymers Gels Netw. 387, 3 (1995)

37. J.P. Gong, T. Nitta, Y. Osada, J. Phys. Chem. 9583, 98 (1994)

38. Y. Osada, H. Okuzaki, H. Hori, Nature 242, 355 (1992)

39. A.K. Bajpai, S.K. Shukla, S. Bhanu, S. Kankane, Prog. Polym. Sci. 1088, $33(2008)$

40. R. Luo, H. Li, E. Birgersson, K.Y. Lam, J. Biomed. Mater. Res. 248, 85 (2008)

41. E. Papajová, M. Bujdoš, D. Chorvát, M. Stach, I. Lacík, Carbohydr. Polym. 472, 90 (2012)

42. A. Vikartovská, M. Bučko, D. Mislovičová, V. Pätoprstý, I. Lacík, P. Gemeiner, Enzym. Microb. Technol. 748, 41 (2007)

43. S. Obara, T. Yamauchi, N. Tsubokawa, Polym. J. 161, 42 (2010)

44. B.H. Stuart Infrared, Spectroscopy: Fundamentals and Applications (Wiley, 2004)

45. P. Mazancová, N. Némethová, D. Trel’ová, L. Kleščíková, I. Lacik, F. Rázga, Carbhydr. Polym. 104, 192 (2018)

46. G.S. Longo, M.O. de la Cruz, I. Szleifer Soft Matter 8359, 12 (2016)

47. X. Zhan, J. Wang, Z. Xiong, X. Zhang, Y. Zhou, J. Zheng, J. Chen, S.-P. Feng, J. Tang, Nat. Commun. 3921, 10 (2019)

48. S. Zavahir, I. Krupa, S.A.S.A. AlMaadeed, J. Tkac, P. Kasak Environ, Sci. Technol. 9260-9268, 53 (2019)

49. D. Zhao, L.Y. Lee, S.L. Ong, P. Chowdhury, K.B. Siah, H.Y. Ng Sep, Purif. Technol. 339, 213 (2019) 